\title{
Isofrequency broadcast FM System, a RF spectrum optimization experience in Brasil
}

\author{
Evandro Franco Tiziano
}




\title{
Isofrequency broadcast FM System, a RF spectrum optimization experience in Brasil
}

\author{
Evandro Franco Tiziano \\ Akron Technical Service Ltda, Brasil, RJ.
}

This article proposes the description of a 16-year experience of the isofrequency FM operation in Brazil. Starting in Rio de Janeiro (2000). Inclusion of the technology as part of technical rules in the Brazilian Technical Standard (1999) ${ }^{1}$. Recognition by CONFEA $^{2}$ (2014) as local intellectual property ${ }^{3}$ and operation by several FM stations. Solving a coverage problem due to local geography, using same frequency of the main transmission system with no interference in common coverage signal areas and coverage extension using complimentary low power cells. Engineering planning and implementation challenges.

\section{Index Terms - Broadcast, FM, Isofrequency.}

\section{INTRODUCTION}

$T_{\mathrm{b}}^{\mathrm{H}}$ HE isofrequency technique used in Brazilian FM broadcast market was mainly proposed as solution for coverage blocked by geological obstacles in Rio de Janeiro, RJ, Brazil. This is a city with 3 mountains height $1.000 \mathrm{~m}$, within urban area. The restriction is the use of no extra RF spectrum due to local legislation and we could not propose different frequencies like done in RTV analog systems. Considering a new solution, the isofrequency option needed initial tests. Lab system was an option to carry out this task. A restructuration of technical rules linked the evaluation by government. The proposed technology predicted FM analog gap filling and the possibility of coverage enlargement using low power cells. The other idea behind the perspective was the drop of interference caused by intermodulation or harmonic levels present in high power systems.

\section{Proposal AND First StePS}

Firstly, we detected a problem to promote an analysis

\footnotetext{
${ }^{1}$ Resolution 67 ANATEL, item 5.2.9

${ }^{2}$ CONFEA (Brazilian Federal Engineering and Agronomy Council)

${ }^{3}$ CONFEA Certificate $n^{\circ} 2269,2014$ (validating actions since 2000).
}

and subsequent solution synthesis.

The problem: Even $30 \mathrm{KW}$ ERP broadcast FM transmitting systems could not reach a significant population $15 \mathrm{~km}$ away from main transmitter site (720 $\mathrm{m}$ high). Indeed, in the west side of Rio de Janeiro city there are about 2 million people in $(8$ million in total population), blocked by two mountains $1.000 \mathrm{~m}$ high, located west $5 \mathrm{~km}$ and $15 \mathrm{~km}$ respectively from main transmitters. This topography creates an attenuation cone for the "Campo Grande" urban area with 2.000.000 potential listeners near see level. Besides, even the $5 \mathrm{~km}$ block has 500.000 potential listeners in the "Jacarepaguá" area not totally attended by good FM signal.

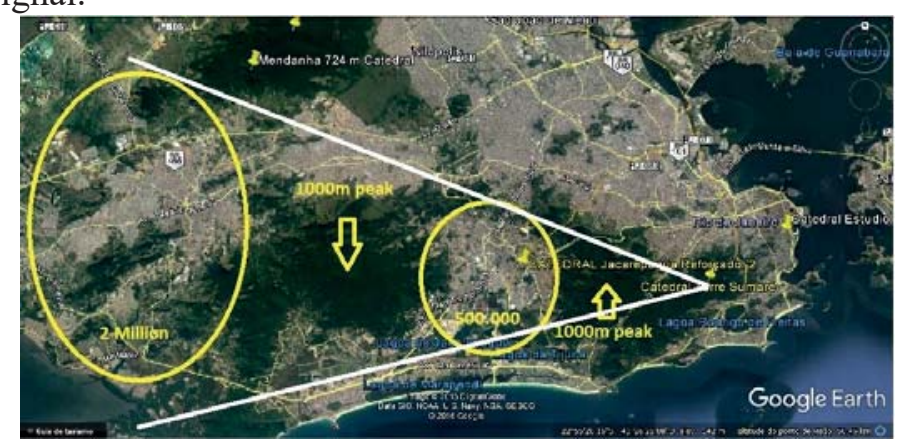

Fig. 1 Unattended coverage areas by main $30 \mathrm{Kw}$ transmitter indicated by "Catedral Torre Sumaré" (723 m high).

The analysis continued, measuring field strength in the areas with bad signal and the area with good signal nearby. Those areas would be the common area where both signals would be relevant for reception. We selected this area in a Road called Av. Brasil in a neighbor called Vila Kennedy.

\section{A. Solution synthesis steps}

In all innovative solutions, some parameters were essential:

-Technical capability - design, lab and field skills.

-Opportunity - a real case and legal authorization.

-Financing - a sponsor to support. 


\subsection{Technical parameters, Design...}

To be able to sum two signals on air it was essential the PRECISION. How to reach and keep transmission parameters within severe precise status and maintain this precision along time, in order to have identical signals when both FM signals reach each other. How phase, level and frequency would affect receiver demodulation capability in an asynchronous system? Considering no sync signal reference at receiver side. After some research a company called $\mathrm{PTF}^{4}$, CEO David Briggs bought the idea and joined us in the research and tests.

\subsection{Lab Tests, Equipment challenges:}

In order to establish some parameters, a model was necessary. The tools used were modified low-level synthesizers, calibrated cables, common oscillator reference, spectrum analyzer and a reliable receiver, with controlled input level. We supply audio via a common source, mono in the beginning, then stereo mpx.

Once concluded, when no audio distortion was noticeable, a new step popped up: available market equipment and RF final tests (in the field).The step next was to establish a method of correcting phase in the field. Considering a TUBE transmitter as the main source, changing characteristics as tube goes. The option was build several defined angle cables to be connected in series in the field...considering the FM test frequency $106.7 \mathrm{MHz}$. For precision, we used GPS with $10 \mathrm{MHz}$ reference, calibrated by local Stratum Zero Lab.

\subsection{Final System, Field challenges}

Once approved by client, the Catholic Church Foundation $^{5}$ was time to build a commercial system. We put together new FM exciters, designed antennas to fulfill the desired area and lab equipment for field measurements.

Installation setup: we defined firstly the set at main transmitter site and then the gap filler, a point in the middle of equal FM signal levels in Av. Brasil, both signals reaching the same intensity, around $40 \mathrm{~dB} \mu \mathrm{V}$, confirmed latter using a field strength meter (useful good reception level). First observation: activating the gap filler, the field drop in the common area, the next observation was an audio distortion. We decided to correct phase at gap filler of transmission site. The gap

\footnotetext{
${ }^{4}$ PTF, Precise Time \& Frequency Inc, Boston, USA

5 Fundação Cultural, Educacional e de Radiodifusão Catedral de São Sebastião do Rio de Janeiro - Rd Catedral - Rio de Janeiro - RJ - 106,7 MHz
}

filler station is located inside the radius of the theoretical contour 74.0 DBu of the main station and must be equal or above class A1. We made several tests until the right result appear. Done, field strength increased at same point and distortion disappeared, so the first on air asynchronous isofrequency FM in Brazil was operational, time to drive back and forth, passing the common area observing any possible disturbance. Days after, we were testing different receivers. The other days, we were inviting the sponsors, other colleagues and finally announcing to the audience.

We achieved success after 90 days of hard labor tests when system operates satisfactory since then.

\section{B. Other Recommendations}

As time passes, we have learned more about those systems. One of the learned lessons was the possibility to have different modulation levels, to be able to identify what system was predominant in certain areas, if the gap filler was predominant, or main signal or vice versa.

Further, we tested different gap filler of antenna configurations, with no significant changes. Different powers were tested and due to ground limits, we can say no significant change was noticeable throughout attended area.

\section{MATH}

We do not consider Math analysis here, because it is an experience description with field and system assembly steps.

\section{A. Equations}

The relevant equation that resume the experience is:

$$
\mathrm{a}=\mathrm{a}
$$

This is the description of an experience were frequency and phase are equal, referenced to GPS. Interesting to know that level is not necessarily equal...We really use different levels until now.

\section{CONCLUSION}

It was an achievement of good results, followed by dozens of radio stations, reaching as result an audience increase using small structures, low power FM broadcast gap fillers and no extra spectrum.

\section{REFERENCES}

[1] E. F. Tiziano, "Registro de Obra Intelectual 2269," CONFEA, Oct 30, 2014

[2] Resolução 67, 1 ed, ANATEL,Brasilia, DF, 1998, www.anatel.gov.br/...olucoes/13-1998/168$\underline{\text { resolucao-67 }}$ 


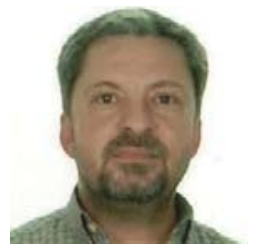

Evandro F. Tiziano, (M'76-SM'81-

F'87) was born in Rio de Janeiro, RJ, Brasil in 1958, graduated in Electrical, Electronic and Telecommunication engineering from Nuno Lisboa University, Rio de Janeiro, in 1981, Specialization in Technology, Labor \& Education at CEFET, Rio de Janeiro, in 2013, Master Degree(in course) in Electrical Engineering, at CEFET, ExMember of the Technical Council in ABERT(Associação Brasileira de Rádio e TV), Technical Manager in Jornal do Brasil Radio Network and Newspaper(), Technical Manager in Manchete Radio and TV Network(), Technical Director in Globo Radio Network. 